\title{
Review
}

Karina Cereceda, Roddy Jorquera and Franz Villarroel-Espíndola*

\section{Advances in mass cytometry and its applicability to digital pathology in clinical-translational cancer research}

https://doi.org/10.1515/almed-2021-0075

Received June 3, 2021; accepted July 16, 2021;

published online November 24, 2021

\begin{abstract}
The development and subsequent adaptation of mass cytometry for the histological analysis of tissue sections has allowed the simultaneous spatial characterization of multiple components. This is useful to find the correlation between the genotypic and phenotypic profile of tumor cells and their environment in clinical-translational studies. In this revision, we provide an overview of the most relevant hallmarks in the development, implementation and application of multiplexed imaging in the study of cancer and other conditions. A special focus is placed on studies based on imaging mass cytometry (IMC) and multiplexed ion beam imaging (MIBI). The purpose of this review is to help our readers become familiar with the verification techniques employed on this tool and outline the multiple applications reported in the literature. This review will also provide guidance on the use of IMC or MIBI in any field of biomedical research.
\end{abstract}

Keywords: imaging mass cytometry (IMC); multiplexed ion beam imaging (MIBI); oncology.

\section{Introduction}

Considerable efforts have been made to try to integrate the different sources of information about tumor biology, such as morphology and genetic features [1-4]; however,

Karina Cereceda and Roddy Jorquera contributed equally to this work.

*Corresponding author: El Dr. Franz Villarroel-Espíndola, Laboratorio de Medicina Traslacional, Instituto Oncológico Fundación Arturo López Pérez, Calle José Manuel Infante no 805, Providencia, Santiago 8320000, Región Metropolitana, Chile,

E-mail: franz.villarroel@falp.org

Karina Cereceda and Roddy Jorquera, Laboratorio de Medicina Traslacional, Instituto Oncológico Fundación Arturo López Pérez, Santiago, Chile technology and classical tools have failed to combine the multiple biomarkers that could be potentially useful for cancer staging or patient-treatment matching, or identifying the correlation between treatment and the expected clinical outcome.

Tumor microenvironment is defined as the extracellular environment and cellular components of the affected organ, surrounding tumor cells. This environment consists of neoplastic and non-neoplastic cells such as fibroblasts, lymphocytes, macrophages and other immune cells, as well as vascular components, and the extracellular matrix itself, including its fluids and dissolved molecules such as secreted cytokines, chemokines, metabolites, and extracellular vesicles [5-7]. There is cumulative evidence demonstrating that non-neoplastic cells residing in tumoradjacent tissues may play an active role in the neoplastic process and even facilitate the evasion of tumor cells from the immune system [7]. In this scenario, tumor microenvironment may promote malignant transformation and progression, metastasis and even resistance to conventional and emerging therapies $[6,8]$.

Over the years, health problems in developed countries have changed as a result of the aging of the population. Thus, chronic multimorbidity, as well as cancer, has become increasingly frequent.

Evidence-based research and technological advances have pushed modern health centers to progressively adopt a holistic, patient-centered care approach [9]. Such advances have also facilitated patient stratification based on enhanced diagnostic tools and on the use of instruments predicting therapy success, especially in cancer patients.

According to the American Society of Clinical Oncology (ASCO), "panomics" is defined as the integration of clinical data with data obtained from analytical or "omic" platforms [10]. This integration strategy has been identified as one of the driving factors that will model the approach to cancer by 2030 [11].

In the field of oncology, the integration of "omics" $[12,13]$, data from electronic clinical records [14] and, more recently, "radiomics", digital pathology, bioinformatics, 
and artificial intelligence [15], among other technological advances, make it possible to stratify patient populations into subpopulations, based on their risk to develop a given condition or respond to a particular therapy.

\section{Multiple component imaging and mass spectrometry}

Recent advances in multiplexed single-cell spatial analysis of tissue specimens have uncovered the complex biology of cancer at an unprecedented resolution [16]. Cutting-edge technology makes it possible to identify the type and status of cells in a tumor and accurately determine their spatial location within the tumor. The combination of these techniques with computational biology will help us better understand tumor progress and heterogeneity in its microenvironment and build models that capture the complexity of pan-omics data in different patients. Ultimately, they will allow us to fine-tune diagnostics and therapeutics [11, 17, 18].

The heterogeneous response of cancer patients to immunotherapy highlights the need to better understand tumor microenvironment [19] and cell interactions within a tumor. This need will expectantly drive the development of new technologies and methods that provide omics data and multiplexed images of tissue specimens [20], ultimately leading to the identification of potential therapeutic targets $[17,21,22]$.

The intensive use of immunohistochemistry (IHC) and imaging techniques in the clinic demonstrates the relevance that spatial information has for digital pathology and clinical-translational research.

In clinical practice, the standard protocol for cancer diagnosis includes the immunohistochemical analysis of a stained paraffin-embedded tissue specimen on a microscope slide [23, 24].

Limitations of conventional IHC include high interobserver variability [25] and the fact that tissue sections can only be stained with two or three markers at a time. This way, to study various biomarkers, it is necessary to analyze multiple tissue sections through serial histological sectioning, which is challenging when only a small sample of tissue is available [24]. This approach limits the possibility of obtaining a general picture of a complex immunological microenvironment. For example, IHC is not useful to characterize subsets of CD8-positive T-cells with different functionalities infiltrating the tumor nest (apoptotic, proliferative, cytotoxic, memory T-cells, to name a few). Also, IHC is not effective in identifying, simultaneously, lymphocyte populations such as
$\mathrm{CD} 8, \mathrm{CD} 4$, and $\mathrm{CD} 20$ in a region of interest [24, 26]. In addition, in a variety of tumors, patient-treatment matching is performed on the basis of the expression of specific molecules such as PD-L1 on tumor cell surface [27, 28]. The presence of lymphocytic inflammatory infiltrate and PD-1 overexpression on the surface of CD8-positive T-cells has been largely proven to predict response to anticancer immunotherapies inhibiting PD-L1/PD-1 binding [22]. These markers may have predictive value either alone or in combination. Some researchers support their combined use, as they have been proven to have prognostic value in several types of cancer [20, 22].

A variety of IHC techniques have been developed to stain and visualize a larger number of molecules in a single tissue section. These techniques, commonly known as multiplexed IHC, combined with the use of fluorescentlabeled secondary antibodies, have made an undeniable contribution to scientific knowledge. IHC, however, has significant limitations, such as spectral interference when more than one fluorescent label is used, cross-reactivity between antibodies, photo-bleaching, fading of the fluorescent dye, and autofluorescence of the tissue [29].

Several cutting-edge methods have the ability to detect multiple components, albeit with lower sensitivity, resolution, or accessibility [30]. Table 1 summarizes the different multiplexed imaging technologies and procedures applied to formalin-fixed tissue sections.

Some of these novel methods are based on cyclic immunofluorescence [31], the use of oligonucleotides as bar codes [19, 30, 32-35], mass spectrometry combined with classic histological techniques and targeted mass spectrometry based on labeled antibodies [36, 37]. These instruments provide a higher phenotypic specificity, as compared to classic IHC. In addition, they allow optimizing specimen use by detecting multiple markers at a time in a single sample section. These instruments also increase the sensitivity of methods through the combined use of several markers for a specific type of cell.

Imaging mass cytometry (IMC) yields images through time-of-flight analysis of rare metal isotopes conjugated to a specific antibody. This way, drawing on the principle described for mass cytometry, each antibody acts both as detector and reporter [38] (Figure 1).

Multiple targets can be detected through the presence of stable isotopes from the lanthanide series, which are chelated using a synthetic polymer containing functional groups 1,4,7,10-tetraazacyclododecane-1,4,7,10-tetraacetic (DOTA) or diethylene triamino pentaacetic (DTPA), which are conjugated to the heavy chain of immunoglobulin $\mathrm{G}(\mathrm{IgG})$ through activated sulfhydryl groups. Near 40 isotopes are widely employed, which are resolved with a precision of a unit of 


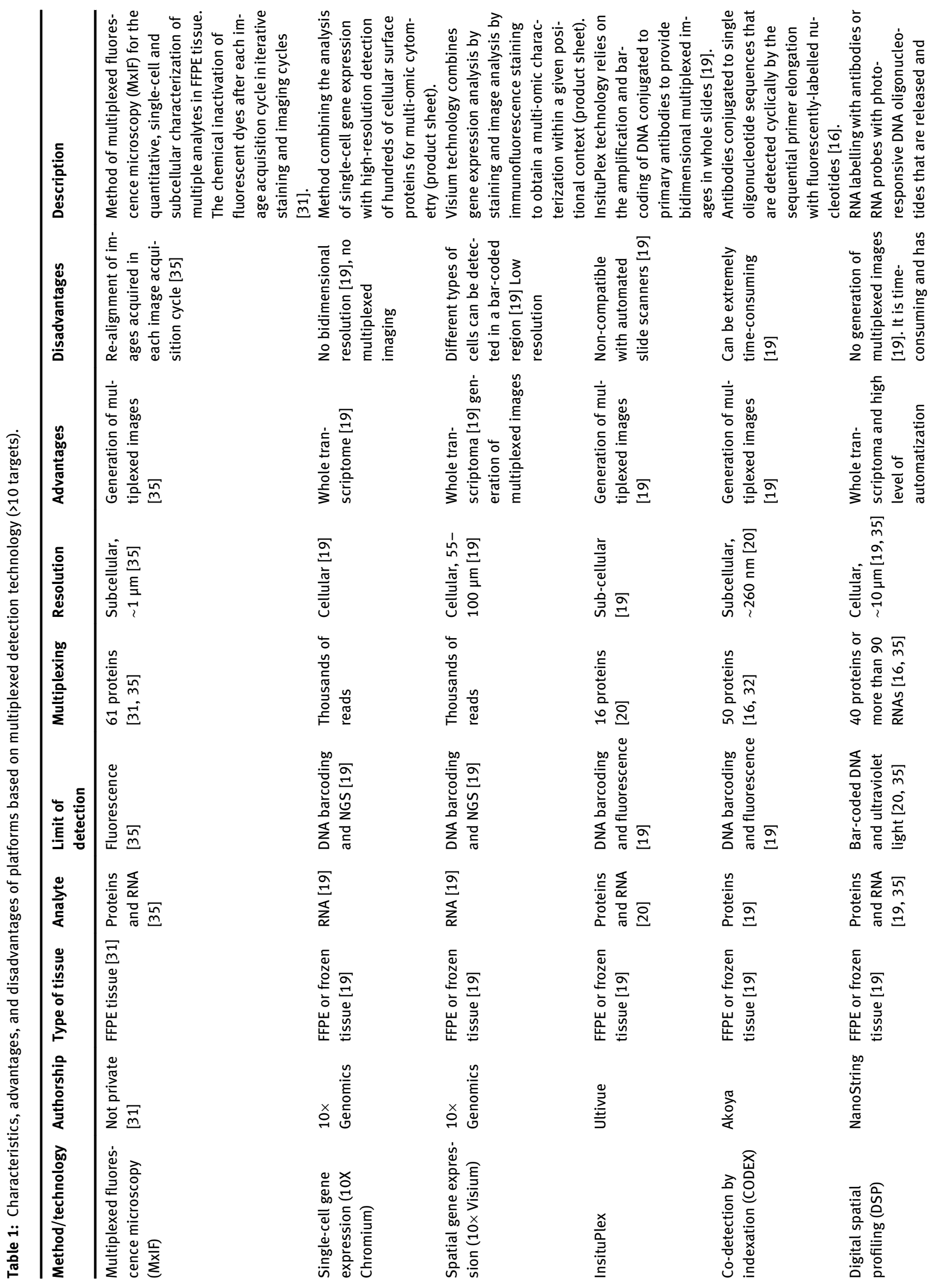




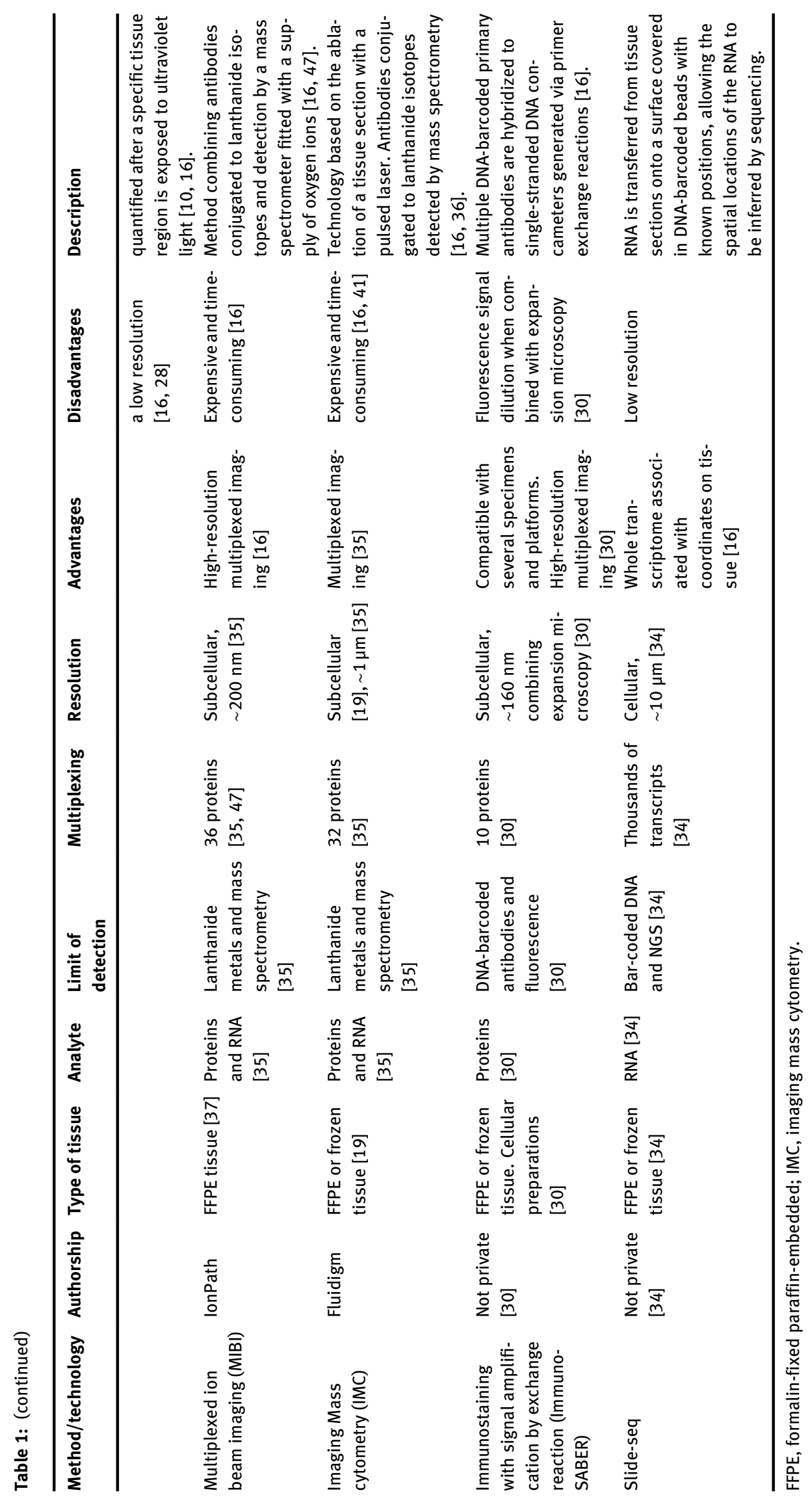




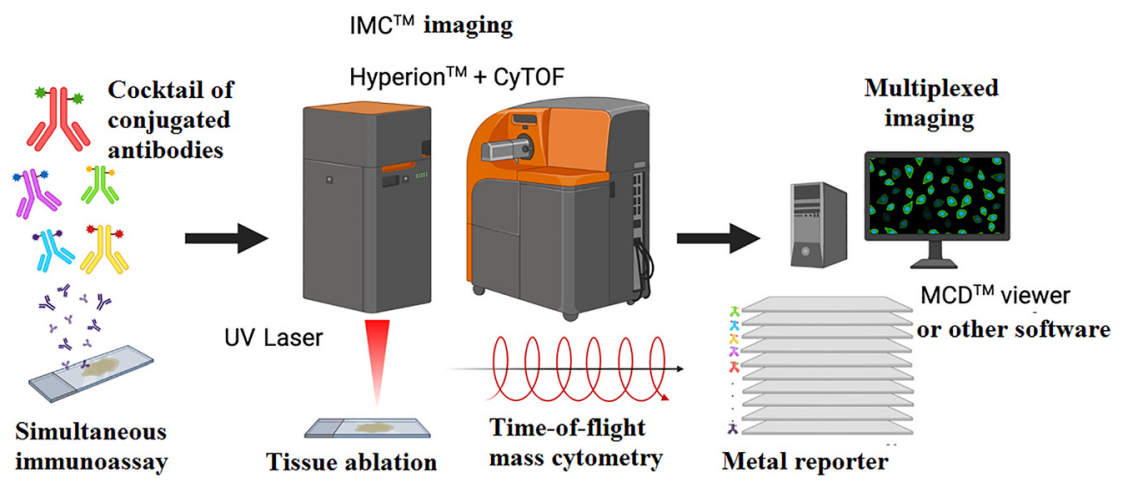

Figure 1: Workflow of imaging mass cytometry (ІМСТM).

Histological tissue sections or immobilized cells are simultaneously immunodetected with multiple antibodies conjugated to different isotopes (reporters). After tissue ablation by pulsed laser on Hyperion ${ }^{\mathrm{TM}}$, the vaporized sample is driven to the mass detector of the mass cytometer $\left(\mathrm{CyTOF}^{\circledR}\right)$ through a plasma flow of inert gas. A set of coordinates allows reconstructing the tissue and the association with the abundance of each reporter. Different tools enable signal (image) analysis and overlapping. Figure designed by https://app.biorender.com/.

atomic mass in more than $95 \%$ of cases, and for which there is an optimized conjugation protocol [39].

From the point of view of imaging, IMC technology permits the ablation of tissue or immobilized cells on a conventional silicate glass using a pulsed laser operating at $213 \mathrm{~nm}$ and focused to a $1 \mu \mathrm{m}$ diameter spot size. The sample is vaporized on each laser shot and carried into the mass cytometer by the stream of plasma of an inert gas. Apart from the cloud of atoms, each laser shot generates a set of coordinates that allows us to reconstruct the tissue and associate it with the abundance of reporters in each event [38].

MIBI enables the characterization of histological sections based on metal-labeled antibodies [37]. It is very similar to IMC but ablation is performed under different conditions. Although MIBI uses a beam of oxygen ions in a vacuum chamber, IMC employs a laser in a chamber at atmospheric pressure. In general, the two technologies seem to be comparable in terms of sensitivity, resolution, and complexity of results [40]. In some cases, when combined with other technologies such as transcriptomic analysis at single-cell resolution, these methods might provide valuable information about the biological complexity of tumor microenvironment.

A review is provided below of the main hallmarks in the development of multiplexed imaging both, by IMC and MIBI, and its application to clinical-translational research.

\section{Timeline of the analysis of multiplexed images}

The information provided by imaging mass spectrometry has made it possible to develop therapeutic and diagnostic models that could help classify patients based on tumor cell phenotype and genotype or on the architectonic features of neighboring structures. Different scientific, academic and clinical groups are currently using these tools to perform tissue segmentation and phenotypic profiling at diagnosis, start of therapy and throughout the treatment (Table 2).

\section{Mass cytometry in histology}

In 2014, Giesen et al. reported the usefulness of cytometry by time-of-flight (CyTOF) for the analysis of suspended tissue specimens to acquire multi-parametric images using CyTOF technology. This study was performed in malignant breast lesions and their respective non-tumor controls, where each antibody was covalently bounded to the detection metal isotope to analyze 32 proteins separately at subcellular resolution. Building a high-dimensional image involves overlapping the flight times of each reporter with the coordinates of the ablation laser. This way, a multidimensional and multi-parametric composition is obtained with the spatial resolution required to perform segmentation and phenotyping studies [41]. The authors previously assessed the concordance between staining patterns and signal intensities for each antibody by classic immunodetection, and defined variations between metal-conjugated antibodies and unconjugated antibodies.

Signal intensity variability ranged between $2-27 \%$, but no variability was observed in staining patterns. This difference was attributed to intrinsic variation among staining agents in serial non-identical tissue sections [36]. Computational analysis and bioinformatics demonstrated that 


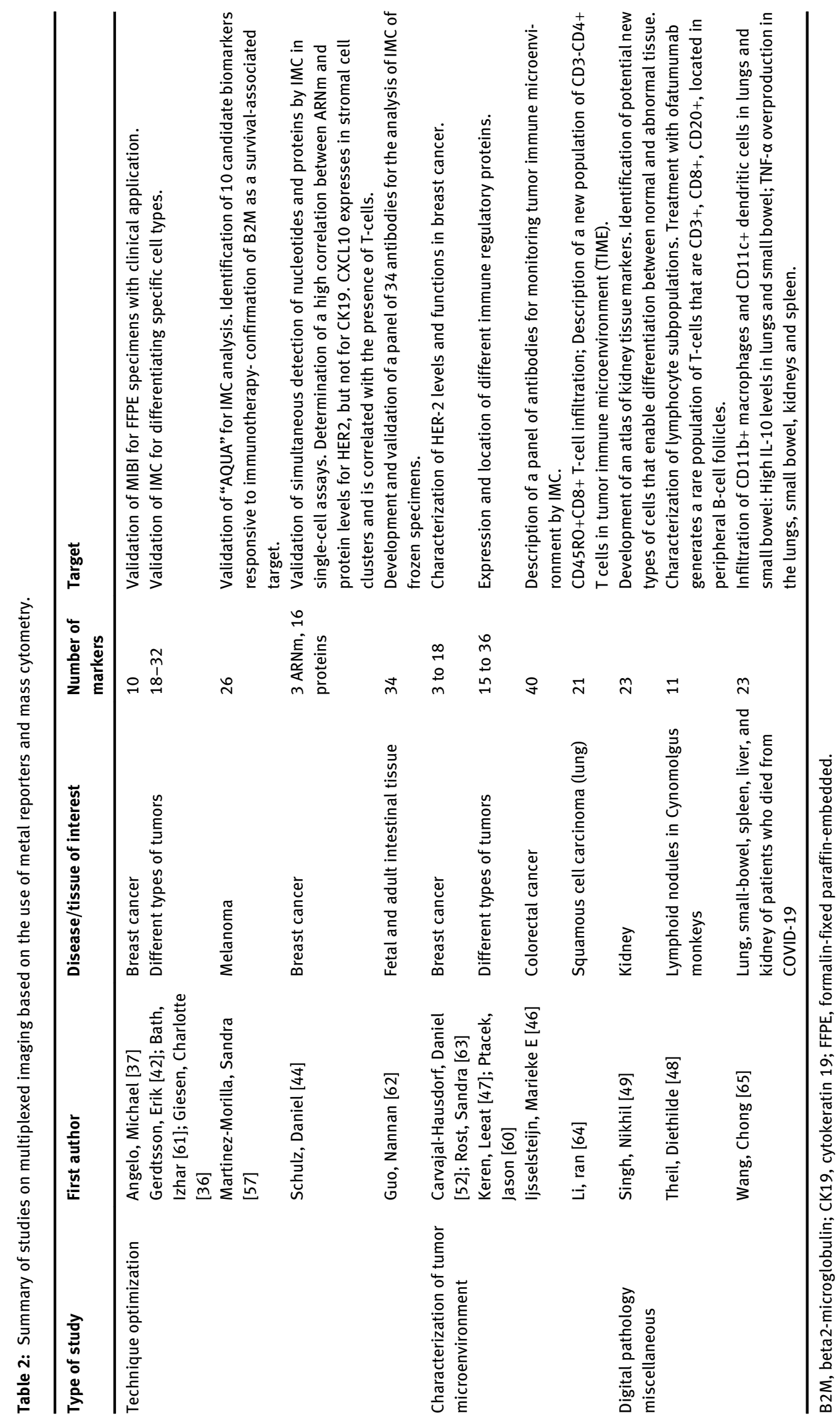


imaging mass cytometry (IMC) was highly sensitive, reproducible, and comparable to the images obtained by conventional IHC, immunocytochemistry, and immunofluorescence and, in addition, make it possible to distinguish the structure and features at the level of single-cells and from whole-tissue sections.

The use of IMC for the analysis of individual cells' spread after the publication of the study by Gerdtsson et al. [42], who integrated high-definition single-cell analysis (HD-SCA) [43] and IMC. This technique enabled the morphological analysis and phenotyping of single rare cells, circulating tumor cells, disseminated tumor cells, and minimal residual disease. Based on human cancer-derived cell lines (LNCap in prostate and MDA-MB-231 in breast cancer), the authors established the conditions of sensitivity, specificity, and linearity for the detection of these cellular fractions within a human wholeblood matrix. The tumor cell is identified in the leukocyte smear by fluorescent staining with cytokeratin and CD45; then, labeling with metal reporters is performed using the battery of selected antibodies. Based on the spatial coordinates previously obtained by laser ablation, the authors acquired $400 \times 400$ um images of the region of interest with a resolution of $1 \mathrm{um}^{2}$ using a laser pulse of $200 \mathrm{~Hz}$. With a relatively small antibody panel, the quality of the image obtained by IMC allowed the authors to individualize neoplastic cells at a relative abundance of one per 10,000 nucleated blood cells. Notably, owing to the signal-to-noise ratio and limit of detection established by the authors, historical samples could be re-analyzed and compared with previously reported findings, with a high level of concordance [42].

Due to their versatility, IMC reporters are used for the detection of oligonucleotides and nucleic acids. In the past, nuclear components could be evaluated using DNA intercalating agents or by the detection of some histone. However, Schulz et al. [44] suggest that messenger RNA (mRNAs) and protein levels can be determined in histological samples at the same time. The main contribution of these authors was that they modified the RNAscope ${ }^{\circledR}$ protocol [45] for in-situ hybridization and replaced the detection probe with an oligonucleotide conjugated to a metal reporter for IMC staining. Once hybridization is completed, the tissue or specimen was ready for later processing, including immunodetection for IMC.

To validate this novel application, the authors assessed concordance between fluorescence in-situ hybridization (FISH) and the signal from the metal reporter conjugated to the probe, considering the detection of mRNA of constitutive genes (POLR2A, PPIB, and UBC) in paraffin-embedded HeLa cells. The correlation between detection methods ranged from 0.89 to 0.8 [44].
In very general terms, the ability of this new method to detect nucleic acids and proteins simultaneously was verified in 70 patients with breast cancer considering 16 target proteins and three target RNAs. To such purpose, the authors assessed the correlation between the abundance of proteins and mRNAs for human epidermal growth factor receptor 2 (HER2) and cytokeratin 19 (CK19). However, results were not conclusive, and it could be attributed to some regulatory mechanism other than those addressed in the experiment. In any case, this technique allows the detection of mRNA and proteins at a time, providing a detailed cellular, phenotypic and functional characterization of single-cells in FFPE by IMC.

Finally, from a methodological point of view, several authors have generously shared their experiences and published their results. A recent paper summarizes antibody staining and handling conditions for a panel of 40 biomarkers, with special relevance given to antigen recovery conditions. The authors compared the $\mathrm{pH}$ of the recovery buffer at standard temperature and pressures, and found that for their selected antibodies, a low $\mathrm{pH}$ (10 $\mathrm{mM}$ Citrate $\mathrm{pH}=6$ ) would have a favorable effect, as compared to a high $\mathrm{pH}(10 \mathrm{mM}$ Tris/1 mM EDTA $\mathrm{pH}=9)$, based on individual IHC results and detection by DAB staining. After having evaluated 65 antibodies, Ijsselsteijn et al. [46] selected 40 monoclonal antibodies and reported their conjugated versions, incubation conditions and working dilutions. Unfortunately, the authors did not report the concentrations of each stock, which prevent homologation. However, this explanatory and detailed paper is very useful when it comes to design an IHC protocol for IMC.

\section{MIBI, a new kid on the block}

Among IMC tools, the one designed by Angelo et al. [37] and later improved with the integration of time-of-flight analysis [47] has been proven to be highly reproducible and reliable for the analysis of fresh and paraffinembedded tissue specimens. The first experiences with multiplexed ion beam imaging (MIBI) were based on the use of peripheral blood mononuclear cells (PBMC), which were labeled in suspension using classic surface markers such as CD3, CD4, and CD8 for T-lymphocytes, CD14 mainly for monocytes, CD19 for B-lymphocytes, and generic markers for immune cells CD45 and HLA-DR. Two identical fractions were generated, a cellular fraction was embedded in silicone for MIBI, whereas the other was processed for mass cytometry (CyTOF). The analysis showed a high 
correlation between the two tools in signal intensity and absolute count of the elements detected for each category, with a dynamic range of 10,000 counts for MIBI and a variance $<1 \%$ between mass cytometry and imaging analysis. In addition, based on the staining strategy employed, MIBI may allow for the analysis of isolated cells and/or cells grown in suspension without needing a smear or imprint; this technique offers the possibility of centrifuging and embedding cells in silicone or other compatible substrate. In this context, FFPE tissues have also been analyzed by MIBI in accordance with the following method: 5 um-thick samples were directly labeled with initial combinations of 10 antibodies [37], then the panel was progressively increased up to 40 [47].

It is worth mentioning that the results of the histological analyses performed on MIBI images were consistent with those of classic IHC tools. Angelo [37] demonstrated that the specificity of the primary antibody is maintained after it is modified chemically, with a signal intensity and noise comparable to those of chromogenic staining. In addition, automated quantitative image analysis based on bioinformatics was proven to be compatible, with a high concordance with the validated diagnostic tools currently available (for example QIA, quantitative image analysis FDA-approved), with an $\mathrm{H}$ score of 1.06.

In accordance with different authors, MIBI has multiple advantages over conventional IHC. (i) Higher sensitivity and analytical dynamic range, increasing 100 and 1,000 times signal-to-noise ratio, as compared to fluorescence and chromogenic staining, respectively; (ii) higher specificity, albeit it depends on the primary antibody employed. The high analytical resolution of mass analysis (mole Dalton's fraction) prevents spectral overlapping between adjacent reporters and the multiplicity of detectable targets; (iii) an optimized use of scarce biological material. Reporters are highly stable in time, and samples can be repeatedly scanned at different resolutions (from $260 \mathrm{~nm}$ to $1 \mathrm{um}$ ).

More recently, MIBI demonstrated to be useful in the study of triple-negative breast cancer with a large panel of 36 target proteins. This technique has revealed that some of the phenotypic characteristics of the tumor are related to the architecture of the tissue and its neighboring environment [47]. Some authors describe a heterogeneous distribution of positive PD-L1 tumor and non-tumor cells within and between subjects. Researchers have also observed a high abundance of positive HLA-DR cells in tumor margins and stromal area, which could be associated with higher survival rates [47].

\section{Innovative applications}

\section{Non-human models}

IMC has shown an unexpected versatility, having been used not only in human but also in animal tissue. Considering all guidelines for the validation of antibodies and the conditions for immunodetection described above, Theil et al. [48] established a panel of nine antibodies to characterize lymphocyte subgroups in blood and lymphoid tissue in Cynomolgus monkeys, who received Ofatumumab at doses equivalent to those employed in humans [48]. The IMC technique has shown high plasticity and is gaining ground in studies with a higher impact on human health. Ofatumumab is the first anti-CD20 monoclonal antibody to be tested in a phase III trial for the treatment of multiple sclerosis.

\section{Physiopathology of kidney disease}

Efforts to reproduce the complexity of healthy and unhealthy human tissue have intensified significantly in the recent years. Singh et al. [49] used a set of 23 antibodies to create a 2-dimensional atlas of the human kidney at a very high resolution level, exploring the tissue from the cortex through the renal medulla. The high sensitivity, specificity, and multiplicity of signals enabled the authors to characterize transitional tubular regions, which had never been described in such detail before [49]. Additionally, the authors analyzed pathological tissue and paid special attention to populations of infiltrating immune cells in a setting of kidney transplantation and nephritis. The validation of antibodies and protocols was shared on (Re)Building a Kidney (https://www.rebuildingakidney.org/) [50].

\section{HER2 and trastuzumab}

From the point of view of cancer research, IMC and other technologies have made a valuable contribution to knowledge, especially regarding the development of biomarkers. At present, trastuzumab is a therapeutic antibody widely used in breast cancer in which binding site is located at the extracellular domain (ECD) of HER2 [51]. One of the advantages of IMC is that it allows the evaluation of a single marker from two perspectives. Carvajal-Hausdorf et al. [52] included two anti-HER2 antibodies in the same panel in which specificities were directed towards an 
epitope on the ECD and an epitope on the intracellular domain (ICD). After a retrospective analysis of breast cancer biopsies, the authors found that the specimens of the patients who experienced recurrence after adjuvant trastuzumab were rarely HER2 ECD-positive. Clinically, an elevated ECD/ICD ratio would be associated with a recurrence-free survival $>5$ years and with a significant abundance of positive CD8 cytotoxic lymphocytes in neighboring tissues. Although only 16 antibodies were tested in that study, the orthogonal validation performed by Carvajal-Hausdorf et al. added to previous evidence on the role of HER2 domains reported by the same group, suggesting that simultaneous classic immunodetection of one or two markers is useful after the variables with a lower significance have been excluded.

\section{Strategies of analysis}

With regard to image analysis strategies, most authors used Fluidigm $\mathrm{MCD}^{\mathrm{TM}}$ viewer [53]. This application identifies the levels detected by each metal reporter and provides its geographic location in the tissue. However, the most relevant primary and secondary analyses were performed using the tools described by Dr. Bernd Bodenmiller, from the University of Zurich in Sweden [54-56]. These are open access applications that allow for signal quantification and segmentation into tissue areas, identification of attributes, and phenotyping, for an appropriate multi-parametric analysis.

Recently, the group led by David Rimm at Yale University, USA, reported the use of AQUA ${ }^{\mathrm{TM}}$ (Navigate BioPharma Inc) for the primary analysis of IMC images [57]. This group is highly experienced in the use of this software for quantitative fluorescence analysis, where tumor regions are identified using a mask associated to a pixel $[58,59]$. Martínez-Morilla et al. analyzed malign melanoma lesions using $A Q U A^{\mathrm{TM}}$, which takes pixels from the reactive areas for the DNA intercalator (Ir191/193) and for HMB45+S100 to generate masks for tissue and tumor, respectively. Likewise, the authors performed digital profiling of tissue and other cells, based on the density of pixels for each reporter. Initially, the authors included 26 antibodies; however, this simplified method of analysis enabled the authors to identify 12 markers significantly associated with progression-free survival and only seven antibodies were related to overall survival. The role of beta-2-microglobulin as a biomarker of survival in patients with metastatic melanoma and immunotherapy has been validated by mRNA analysis and simple fluorescence detection; therefore, this protein emerges as a promising biomarker [57].
At present, other private actors have contributed to the development of user-friendly tools such as those developed by Indica labs $\left(\mathrm{HALO}^{\circledR}\right.$ ) and Visiopharm ${ }^{\circledR}$.

\section{Validation of multiple components}

Other researchers recently assessed the capacity of MIBI to analyze multiple types of solid tumors in different organs and tissues. The study considered 15 types of tumors, including adenocarcinoma, squamous carcinoma and hematologic neoplasms [60]. As their predecessors, the authors evaluated the specificity and sensitivity of their panel of antibodies by IHC, considering endogenous positivity and negativity controls within the same section of tissue. A panel of 15 antibodies was used for immunodetection in $1 \mathrm{~mm}$ tissue sections. Images were acquired in optic fields of $0.25 \mathrm{~mm}^{2}(0.5 \mu \mathrm{m}$ per pixel). A contribution of these authors is that they applied a simple leave-one-out (LOO) statistical method to verify the signals obtained and avoid contamination between neighboring reporters. Staining was successively repeated after a specific antibody was left out from the panel. The results obtained with the entire panel (15 antibodies) were compared with those after an antibody was left out (14 antibodies). After comparison of eight panels, linear regression analysis was performed, with a correlation $\mathrm{R} 2=0.99-1.00$, which indicates no interference across signal sources. Based on this premise, the authors carried out tissue segmentation and cellular phenotyping in each of the tumors selected. The results confirmed the high heterogeneity of the components of immune infiltrate, both in terms of abundance and distribution not only across patients with different types of tumors but also with the same type of lesion [60].

\section{Conclusions}

To decide which technique is the most appropriate in each case, specialists must be aware of the advantages and disadvantages that IMC (including MIBI) has over classic IHC considering their shared features and the fundamentals of multiplexed imaging detection (Table 3).

Nevertheless, both IMC and MIBI allow for the acquisition of complex images with spatial resolution, and the quantification of multiple components at the same time. It is worth noting that the two approaches are similar to classic histological techniques in terms of specificity and sensitivity. From the point of view of quantification, precision and reproducibility, IMC and MIBI have shown to be comparable 
Table 3: Advantages and disadvantages of tools for analyzing biomarkers on formalin-fixed paraffin-embedded tissue samples.

\begin{tabular}{|c|c|c|c|c|c|c|}
\hline \multirow[t]{2}{*}{ Tool } & \multicolumn{2}{|c|}{ Use of tissue } & \multicolumn{2}{|c|}{ Potential targets } & \multicolumn{2}{|c|}{ Reporters } \\
\hline & Advantage & Disadvantage & Advantage & Disadvantage & Advantage & Disadvantage \\
\hline $\begin{array}{l}\text { Classic } \\
\text { immunohistochemistry }\end{array}$ & $\begin{array}{l}\text { Preserves the } \\
\text { slide for mul- } \\
\text { tiple reads }\end{array}$ & $\begin{array}{l}\text { Multiple slides } \\
\text { for complex } \\
\text { studies }\end{array}$ & $\begin{array}{l}\text { From } 1 \text { to } 2 \text { tar- } \\
\text { gets (plus nu- } \\
\text { clear contrast). } \\
\text { The marker can } \\
\text { be analyzed by } \\
\text { multiple } \\
\text { observers. }\end{array}$ & $\begin{array}{l}\text { Restricted number } \\
\text { of combinations } \\
\text { due to the method } \\
\text { of detection and } \\
\text { location of the } \\
\text { marker. }\end{array}$ & $\begin{array}{l}\text { Mostly, insoluble } \\
\text { chromogenic de- } \\
\text { posits stable in } \\
\text { time. }\end{array}$ & $\begin{array}{l}\text { Limited number of } \\
\text { options (enzymes, } \\
\text { conjugates, and } \\
\text { chromogenic } \\
\text { substrates) }\end{array}$ \\
\hline $\begin{array}{l}\text { Multiplexed fluoro- } \\
\text { metric immunoassay }\end{array}$ & $\begin{array}{l}\text { Requires a } \\
\text { lower number } \\
\text { of slides in } \\
\text { complex } \\
\text { studies }\end{array}$ & $\begin{array}{l}\text { Slides can be } \\
\text { preserved for } \\
\text { further reads }\end{array}$ & $\begin{array}{l}\text { Up to } 9 \text { targets } \\
\text { depending on } \\
\text { the platform. Al- } \\
\text { lows multiple } \\
\text { signals from } \\
\text { similar } \\
\text { locations. }\end{array}$ & $\begin{array}{l}\text { Requires thorough } \\
\text { validation, expen- } \\
\text { sive validation. }\end{array}$ & $\begin{array}{l}\text { Multiple combina- } \\
\text { tions based on the } \\
\text { supplier. Allows the } \\
\text { use of signal } \\
\text { amplifiers. }\end{array}$ & $\begin{array}{l}\text { Risk of photo- } \\
\text { bleaching and } \\
\text { spectral over- } \\
\text { lapping of close } \\
\text { fluorescent signals. }\end{array}$ \\
\hline $\begin{array}{l}\text { Multiplexed } \\
\text { immunohistochemistry }\end{array}$ & $\begin{array}{l}\text { Requires a } \\
\text { lower number } \\
\text { of slides in } \\
\text { complex } \\
\text { studies }\end{array}$ & $\begin{array}{l}\text { Tissue destruc- } \\
\text { tion. A second } \\
\text { read is rarely } \\
\text { possible }\end{array}$ & $\begin{array}{l}\text { Up to } 60 \text { targets } \\
\text { based on the } \\
\text { platform. Allows } \\
\text { multiple signals } \\
\text { from similar } \\
\text { locations. }\end{array}$ & $\begin{array}{l}\text { Requires thorough, } \\
\text { expensive } \\
\text { validation. }\end{array}$ & $\begin{array}{l}\text { Multiple combina- } \\
\text { tions based on the } \\
\text { supplier. Possibil- } \\
\text { ities of reporters } \\
\text { overlapping is } \\
\text { limited. }\end{array}$ & $\begin{array}{l}\text { Commercially avail- } \\
\text { able or prepared at } \\
\text { the lab. Expensive } \\
\text { reagent. Limited } \\
\text { use of signal } \\
\text { amplifiers. }\end{array}$ \\
\hline
\end{tabular}

and robust in different matrices and targets, regardless of the complexity or simplicity of the antibody panel.

\section{Perspectives}

It is necessary to determine the abundance and spatial distribution of biomarkers to better understand the physiological processes that occur in normal and tumor tissue. In complex diseases such as cancer, being aware of the correlation between the genotype and phenotype of the different cell components and neighboring structures is crucial to make therapeutic decisions, measure clinical benefit, and reduce therapeutic failures. The acquisition of multiplexed images by IMC, MIBI, or other tools has been extensively validated and verified by different researchers, although a technique of reference is necessary to anticipate deviations. This review is intended to provide an overview of the technologies currently available for research, based on a thorough selection of the literature to reduce the learning curve and facilitate the achievement of results.

Research funding: This Project was funded by the Instituto Oncológico Fundación Arturo López Pérez (grant no. FALPLMT-2021).
Author contributions: All authors have accepted responsibility for the entire content of this manuscript and approved its submission.

Competing interests: Authors state no conflict of interest. Informed consent: Not applicable.

Ethical approval: Not applicable.

\section{References}

1. Coudray N, Tsirigos A. Deep learning links histology, molecular signatures and prognosis in cancer. Nat Cancer 2020;1:755-7.

2. Fu Y, Jung AW, Torne RV, Gonzalez S, Vöhringer H, Shmatko A, et al. Pan-cancer computational histopathology reveals mutations, tumor composition and prognosis. Nat Cancer 2020;1:800-10.

3. Kather JN, Heij LR, Grabsch HI, Loeffler C, Echle A, Muti HS, et al. Pan-cancer image-based detection of clinically actionable genetic alterations. Nat Cancer 2020;1:789-99.

4. Subramanian I, Verma S, Kumar S, Jere A, Anamika K. Multi-omics data integration, interpretation, and its application. Bioinf Biol Insights 2020;14:1177932219899051.

5. Jain RK. Normalizing tumor vasculature with anti-angiogenic therapy: a new paradigm for combination therapy. Nat Med 2001;7:987-9.

6. Trédan 0, Galmarini CM, Patel K, Tannock F. Drug resistance and the solid tumor microenvironment. J Natl Cancer Inst 2007;99: 1441-54.

7. Fridman WH, Pagès F, Sautès-Fridman $C$, Galon J. The immune contexture in human tumours: impact on clinical outcome. Nat Rev Cancer 2012;12:298-306. 
8. Havel JJ, Chowell D, Chan TA. The evolving landscape of biomarkers for checkpoint inhibitor immunotherapy. Nat Rev Cancer 2019;19:133-50.

9. Gabutti I, Mascia D, Cicchetti A. Exploring "patient-centered" hospitals: a systematic review to understand change. BMC Health Serv Res 2017;17:364.

10. Li G, Bankhead P, Dunne PD, O'Reilly PG, James JA, Salto-Tellez M, et al. Embracing an integromic approach to tissue biomarker research in cancer: perspectives and lessons learned. Brief Bioinform 2017;18:634-46.

11. Yu P, Artz D, Warner J. Electronic health records (EHRs): supporting ASCO's vision of cancer care. Am Soc Clin Oncol Educ Book 2014:225-31. https://doi.org/10.14694/edbook_am.2014. 34.225.

12. Yu K-H, Snyder M. Omics profiling in precision oncology *. Mol Cell Proteomics 2016;15:2525-36.

13. Mullish BH, Osborne LS, Marchesi JR, McDonald JA. The implementation of omics technologies in cancer microbiome research. Ecancermedicalscience 2018;12:864.

14. Pendergrass SA, Crawford DC. Using electronic health records to generate phenotypes for research. Curr Protoc Hum Genet 2019; 100:e80.

15. Hulsen T, Jamuar SS, Moody AR, Karnes JH, Varga O, Hedensted S, et al. From big data to precision medicine. Front Med 2019;6:34.

16. de Vries NL, Mahfouz A, Koning F, de Miranda NFCC. Unraveling the complexity of the cancer microenvironment with multidimensional genomic and cytometric technologies. Front Oncol 2020;10:1254.

17. Rozenblatt-Rosen 0 , Regev A, Oberdoerffer P, Nawy T, Hupalowska A, Rood JE, et al. The human tumor atlas network: charting tumor transitions across space and time at single-cell resolution. Cell 2020;181:236-49.

18. Love-Koh J, Peel A, Rejon-Parrilla JC, Ennis K, Lovett R, Manca A, et al. The future of precision medicine: potential impacts for health technology assessment. Pharmacoeconomics 2018;36:1439-51.

19. Sadeghi Rad H, Bazaz SR, Monkman J, Ebrahimi Warkiani M, Rezaei N, O'Byrne K, et al. The evolving landscape of predictive biomarkers in immuno-oncology with a focus on spatial technologies. Clin Transl Immunol 2020;9:e1215.

20. Tan WCC, Nerurkar SN, Cai HY, Ng HHM, Wu D, Wee YTF, et al. Overview of multiplex immunohistochemistry/ immunofluorescence techniques in the era of cancer immunotherapy. Cancer Commun 2020;40:135-53.

21. Binnewies M, Roberts EW, Kersten K, Chan V, Fearon DF, Merad M, et al. Understanding the tumor immune microenvironment (TIME) for effective therapy. Nat Med 2018;24:541-50.

22. Galon J, Bruni D. Approaches to treat immune hot, altered and cold tumours with combination immunotherapies. Nat Rev Drug Discov 2019;18:197-218.

23. Spanhol FA, Oliveira LS, Petitjean C, Heutte L. A dataset for breast cancer histopathological image classification. IEEE Trans Biomed Eng 2016;63:1455-62.

24. Van Herck Y, Antoranz A, Andhari MD, Milli G, Bechter O, De Smet F, et al. Multiplexed immunohistochemistry and digital pathology as the foundation for next-generation pathology in melanoma: methodological comparison and future clinical applications. Front Oncol 2021;11:1012.

25. Varga Z, Diebold J, Dommann-Scherrer C, Frick H, Kaup D, Noske A, et al. How reliable is Ki- 67 immunohistochemistry in grade 2 breast carcinomas? A QA study of the Swiss Working Group of Breast- and Gynecopathologists. PLoS One 2012;7:e37379.

26. Mazzaschi G, Madeddu D, Falco A, Bocchialini G, Goldoni M, Sogni F, et al. Low PD-1 expression in cytotoxic CD8 tumorinfiltrating lymphocytes confers an immune-privileged tissue microenvironment in NSCLC with a prognostic and predictive value. Clin Cancer Res 2018;24:407-19.

27. Lu S, Stein JE, Rimm DL, Wang DW, Bell JM, Johnson DB, et al. Comparison of biomarker modalities for predicting response to PD-1/PD-L1 checkpoint blockade: a systematic review and metaanalysis. JAMA Oncol 2019;5:1195-204.

28. Bera K, Schalper KA, Rimm DL, Velcheti V, Madabhushi A. Artificial intelligence in digital pathology - new tools for diagnosis and precision oncology. Nat Rev Clin Oncol 2019;16:703-15.

29. Dixon AR, Bathany C, Tsuei M, White J, Barald KF, Takayama S. Recent developments in multiplexing techniques for immunohistochemistry. Expert Rev Mol Diagn 2015;15:1171-86.

30. Saka SK, Wang Y, Kishi JY, Zhu A, Zeng Y, Xie W, et al. ImmunoSABER enables highly multiplexed and amplified protein imaging in tissues. Nat Biotechnol 2019;37:1080-90.

31. Gerdes MJ, Sevinsky CJ, Sood A, Adak S, Bello MO, Bordwell A, et al. Highly multiplexed single-cell analysis of formalin-fixed, paraffinembedded cancer tissue. Proc Natl Acad Sci 2013;110:11982-7.

32. Goltsev Y, Samusik N, Kennedy-Darling J, Bhate S, Hale M, Vazquez G, et al. Deep profiling of mouse splenic architecture with CODEX multiplexed imaging. Cell 2018;174:968-81.e15.

33. Merritt CR, Ong GT, Church SE, Barker K, Danaher P, Geiss G, et al. Multiplex digital spatial profiling of proteins and RNA in fixed tissue. Nat Biotechnol 2020;38:586-99.

34. Rodriques SG, Stickels RR, Goeva A, Martin CA, Murray E, Vanderburg CR, et al. Slide-seq: a scalable technology for measuring genome-wide expression at high spatial resolution. Science 2019;363:1463-7.

35. Decalf J, Albert ML, Ziai J. New tools for pathology: a user's review of a highly multiplexed method for in situ analysis of protein and RNA expression in tissue. J Pathol 2019;247:650-61.

36. Giesen C, Wang HAO, Schapiro D, Zivanovic N, Jacobs A, Hattendorf B, et al. Highly multiplexed imaging of tumor tissues with subcellular resolution by mass cytometry. Nat Methods 2014;11:417-22.

37. Angelo M, Bendall SC, Finck R, Hale MB, Hitzman C, Borowsky AD, et al. Multiplexed ion beam imaging of human breast tumors. Nat Med 2014;20:436-42.

38. Chang Q, Ornatsky OI, Siddiqui I, Loboda A, Baranov VI, Hedley DW. Imaging mass cytometry. Cytom A 2017;91:160-9.

39. Hartmann FJ, Simonds EF, Vivanco N, Bruce T, Borges L, Nolan GP, et al. Scalable conjugation and characterization of immunoglobulins with stable mass isotope reporters for singlecell mass cytometry analysis. In: McGuire HM, Ashhurst TM, editors. Mass cytometry: methods and protocols. New York, NY: Springer New York; 2019:55-81 pp.

40. Bodenmiller B. Multiplexed epitope-based tissue imaging for discovery and healthcare applications. Cell Syst 2016;2:225-38.

41. Naderi-Azad S, Croitoru D, Khalili S, Eder L, Piguet V. Research techniques made simple: experimental methodology for imaging mass cytometry. J Invest Dermatol 2021;141:467-73.e1.

42. Gerdtsson E, Pore M, Thiele J-A, Gerdtsson AS, Malihi PD, Nevarez R, et al. Multiplex protein detection on circulating tumor cells from liquid biopsies using imaging mass cytometry. Converg Sci Phys Oncol 2018;4. https://doi.org/10.1088/20571739/aaa013. 
43. Marrinucci D, Bethel K, Kolatkar A, Luttgen MS, Malchiodi M, Baehring $\mathrm{F}$, et al. Fluid biopsy in patients with metastatic prostate, pancreatic and breast cancers. Phys Biol 2012;9:16003.

44. Schulz D, Zanotelli VRT, Fischer JR, Schapiro D, Engler S, Lun X-K, et al. Simultaneous multiplexed imaging of mRNA and proteins with subcellular resolution in breast cancer tissue samples by mass cytometry. Cell Syst 2018;6:531.

45. Wang F, Flanagan J, Su N, Wang L-C, Bui S, Nielson A, et al. RNAscope: a novel in situ RNA analysis platform for formalinfixed, paraffin-embedded tissues. J Mol Diagn 2012;14:22-9.

46. Ijsselsteijn ME, van der Breggen R, Farina Sarasqueta A, Koning F, de Miranda NFCC. A 40-marker panel for high dimensional characterization of cancer immune microenvironments by imaging mass cytometry. Front Immunol 2019;10:2534.

47. Keren L, Bosse M, Thompson S, Risom T, Vijayaragavan K, McCaffrey E, et al. MIBI-TOF: a multiplexed imaging platform relates cellular phenotypes and tissue structure. Sci Adv 2019;5: eaax5851.

48. Theil D, Smith P, Huck C, Gilbart Y, Kakarieka A, Leppert D, et al. Imaging mass cytometry and single-cell genomics reveal differential depletion and repletion of B-cell populations following ofatumumab treatment in cynomolgus monkeys. Front Immunol 2019;10:1340.

49. Singh N, Avigan ZM, Kliegel JA, Shuch BM, Montgomery RR, Moeckel GW, et al. Development of a 2-dimensional atlas of the human kidney with imaging mass cytometry. JCl insight 2019;4:e129477.

50. Oxburgh L, Carroll TJ, Cleaver O, Gossett DR, Hoshizaki DK, Hubbell JA, et al. (Re)building a kidney. J Am Soc Nephrol 2017;28:1370-8.

51. Nahta R. Molecular mechanisms of trastuzumab-based treatment in HER2-overexpressing breast cancer. ISRN Oncol 2012;2012: 428062.

52. Carvajal-Hausdorf DE, Patsenker J, Stanton KP, VillarroelEspindola F, Esch A, Montgomery RR, et al. Multiplexed (18-plex) measurement of signaling targets and cytotoxic T cells in trastuzumab-treated patients using imaging mass cytometry. Clin Cancer Res 2019;25:3054-62.

53. MCDSoftware Viewer. Fluidigm. Available from: https://www. fluidigm.com/.

54. Stroka D. Imaging mass cytometry and mass cytometry platform. Available from: https://www.imc.unibe.ch/technologies/ hyperion/data_analysis/.

55. Schapiro D, Jackson HW, Raghuraman S, Fischer JR, Zanotelli VRT, Schulz D, et al. histoCAT: analysis of cell phenotypes and interactions in multiplex image cytometry data. Nat Methods 2017;14:873-6.

56. Zanotelli VRT, Bodenmiller B. IMC segmentation pipeline: a pixel classification based multiplexed image segmentation pipeline. Zenodo; 2017. Available from: https://github.com/ BodenmillerGroup/ImcSegmentationPipeline/tree/v0.9.

57. Martinez-Morilla S, Villarroel-Espindola F, Wong PF, Toki MI, Aung TN, Pelekanou V, et al. Biomarker discovery in patients with immunotherapy-treated melanoma with imaging mass cytometry. Clin Cancer Res 2021;27:1987-96.

58. Camp RL, Chung GG, Rimm DL. Automated subcellular localization and quantification of protein expression in tissue microarrays. Nat Med 2002;8:1323-8.

59. Neumeister VM, Anagnostou V, Siddiqui S, England AM, Zarrella ER, Vassilakopoulou M, et al. Quantitative assessment of effect of preanalytic cold ischemic time on protein expression in breast cancer tissues. JNCI (J Natl Cancer Inst) 2012;104:1815-24.

60. Ptacek J, Locke D, Finck R, Cvijic M-E, Li Z, Tarolli JG, et al. Multiplexed ion beam imaging (MIBI) for characterization of the tumor microenvironment across tumor types. Lab Investig 2020;100: 1111-23.

61. Batth IS, Meng Q, Wang Q, Torres KE, Burks J, Wang J, et al. Rare osteosarcoma cell subpopulation protein array and profiling using imaging mass cytometry and bioinformatics analysis. BMC Cancer 2020;20:715.

62. Guo N, van Unen V, ljsselsteijn ME, Ouboter LF, van der Meulen AE, Chuva de Sousa Lopes SM, et al. A 34-marker panel for imaging mass cytometric analysis of human snap-frozen tissue. Front Immunol 2020;11:1-14.

63. Rost S, Giltnane J, Bordeaux JM, Hitzman C, Koeppen H, Liu SD. Multiplexed ion beam imaging analysis for quantitation of protein expression in cancer tissue sections. Lab Investig 2017;97:992-1003.

64. Li R, Lin Y, Wang Y, Wang S, Yang Y, Mu X, et al. Characterization of the tumor immune microenvironment in lung squamous cell carcinoma using imaging mass cytometry. Front Oncol 2021;11:1034.

65. Wang C, Xu J, Wang S, Pan S, Zhang J, Han Y, et al. Imaging mass cytometric analysis of postmortem tissues reveals dysregulated immune cell and cytokine responses in multiple organs of COVID-19 patients. Front Microbiol 2020;11:1-10.

Article Note: The original article can be found here: https://doi.org/ 10.1515/almed-2021-0051. 